\title{
Accounts Receivable Factoring As A Response To Weak Governance: Panel Data Evidence
}

Daniel J. Borgia, Florida Gulf Coast University, USA

Mushfiq Swaleheen, Florida Gulf Coast University, USA

Travis L. Jones, Florida Gulf Coast University, USA

H. SheltonWeeks, Florida Gulf Coast University, USA

\begin{abstract}
Accounts receivable factoring is a financing arrangement that occurs when a business sells its accounts receivables. Factoring has emerged as the most important source of working capital for small and medium sized enterprises (SMEs) in many economies because weak laws, poor enforcement, and the associated informational opacity put the SMEs at a disadvantage when borrowing. This paper presents an empirical analysis of cross-country differences in factoring activity to determine whether the quality of governance is a significant determinant of the level of factoring activity. Our analysis is based on a reduced form model that relates a country's factoring activity (turnover) to the quality of governance, while controlling for other determinants of factoring discussed in the literature. We use data for a panel of 59 countries, over the period 1995 - 2005. Our findings support the hypothesis that factoring is more prevalent in economies with weak governance. Additionally, we present evidence that factor turnover is decreasing in the incidence of corruption.
\end{abstract}

Keywords: panel data, factoring, governance, economic development

\section{INTRODUCTION}

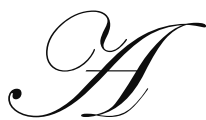

ccounts receivable factoring is a financing arrangement that occurs when a business sells its accounts receivables. The seller of the receivables immediately receives a percentage of the value of the accounts sold, and the buyer of the receivables (the factor) gets the title to the accounts receivables in exchange. After the receivables are collected, the factor forwards the collected balance, less a contractually agreed upon discount, to the seller. According to Factor Chains International (FCI), a global factoring trade group, annual global factoring turnover increased from around $\$ 384$ billion, in 1996, to over $\$ 1,276$ billion, in 2005. Factoring has emerged as the most important source of working capital for small and medium sized enterprises (SMEs) in many economies (Bakker, Klapper and Udell; 2004). This rise in the importance of factoring in recent times, vis-à-vis more traditional financing methods, has captured the attention of many researchers, leading to a growing literature examining the mechanics of factoring and the reasons that explain cross country differences in annual factoring turnover (Lotz, 1992; Mian and Smith, 1992; Bakker, Klapper and Udell, 2004; Berger and Udell, 2004; Klapper, 2000, 2006).

In the prevalent literature, factoring is analyzed in the context of the working of the financial system in an economy. Schumpeter (1911) pointed out that a well functioning financial system is essential for technological progress and economic growth. The efficiency of an economy's financial system in allocating financial resources depends on many factors including the robustness of its financial institutions and financial markets, the strength and integrity of its legal system, and the quantity and reliability of information with which suppliers and demanders of capital are able to assess risk. Weak laws and/or poor enforcement create agency problems that undermine the efficiency of a financial system. In economies with a weak financial system, firms (particularly SMEs) face significant hurdles in obtaining capital from financial institutions and financial markets, sources traditionally used in 
economies with more complete financial systems. Factoring is particularly useful as a source of short-term working capital in such economies because receivables are sold, rather than collateralized, and factored receivables are not part of the estate of a bankrupt firm. In addition, underwriting in factoring is based on the risk of the accounts receivables themselves rather than on the risk of the borrower.

Weak laws, poor enforcement, and the associated informational opacity that put the SME's at a disadvantage as a borrower are rooted in poor governance. When it comes to the working of the financial system, governance problems have added complexities, because they accentuate incentive conflicts and agency problems which are further compounded by government ownership and regulation of the financial institutions (Litan, Pomerleano, and Sundararajan, 2002). The extent to which poor governance has led to the ascendancy of factoring as the preferred short term financing mechanism is an important empirical question, which is yet to be answered.

The objective of the current paper is to fill this gap by presenting an empirical analysis of cross-country differences in factoring activity to determine whether the quality of governance is a significant determinant of the level of factoring activity. Our analysis is based on a reduced form model that relates a country's factoring activity (turnover) to the quality of governance, while controlling for other determinants of factoring discussed in the literature. We use data for a panel of 59 countries over the period 1995 - 2005. Our findings support the hypothesis that factoring is more prevalent in economies with weak governance. Additionally, we present evidence that factor turnover is decreasing in the incidence of corruption.

The paper is organized as follows. In section 2, we present an overview of the literature on accounts receivable factoring. In section 3, we discuss governance and how poor governance constrains access to financing. The data and the empirical strategy are presented in section 4. Our empirical findings are discussed in section 5. Section 6 concludes.

\section{THE CURRENT LITERATURE ON FACTORING}

We start with the mechanics of factoring as discussed in the literature. Factoring accounts receivables simply involves selling a future payment from a customer to a third party, the factor, at a discount in order to receive immediate payment (Spragins, 1991). Most factoring arrangements are executed on a non-recourse basis, wherein the factor assumes the majority of the risk (as well as the wait) of collecting the payment. When a business factors its receivables, no money is borrowed, no money is loaned, and no interest is paid or earned. The factor earns a fee, which is based upon the dollar amount of the invoices/receivables purchased. This fee, earned by the factor, is based on a percentage of the face amount of the invoices, which is determined by the quality, quantity, and average turnover of the account.

Before purchasing receivables, bank or non-bank financial institutions will spend time underwriting both the credit of the client (the business applying for the financing) and especially the client's customers (the businesses paying the receivable). The factoring institution will likely examine the track record of the business' collection ability and the payment history of its customers (Lotz, 1992). The more confidence the factoring institution has in the firm paying the receivables, the more likely it will purchase the accounts receivable. An excellent overview of the mechanics of factoring is provided by Klapper (2006)

The literature points to two major determinants of the level of factoring activity in an economy: first, the availability of financial information about enterprises; and second, the overall level of economic activity. Bushman and Smith (2003) present a framework for understanding the links between the availability of reliable financial information and enterprise level efficiency and firms' choice of financing mechanism. Reliable and adequate information helps to identify promising investment opportunities with less error, lowers the principal-agent problem between shareholders and managers, and reduces the information asymmetry between investors and firms. A lack of adequate financial information, in general, and informational asymmetry between SMEs and financial institutions, in particular, is the most commonly cited reason for the existence and development of factoring. According to Mian and Smith (1992) and Smith and Shnucker (1994), firms factor accounts receivable to better manage their exposure to credit risk. Specifically, a factor that specializes in an industry with many buyers and sellers may be able to pool information among sellers to help reduce credit risk. This suggests that firms incurring larger costs of collecting 
information about the credit-worthiness of its customers should be more likely to factor its accounts receivables. Summers and Wilson (2000) find that a firm's motivation to use factoring is primarily related to its demand for asset-based finance rather than choices related to the organizational structure of the firm. Thus, firms with higher costs of obtaining market-based financing will tend to use factoring to obtain funds. In addition, they assert that aggregate factoring volumes (as a percentage of total sales) should be higher in countries that possess greater information asymmetries resulting from weak legal and governance systems. Thus, we should expect to find that firms in countries with informationally opaque business environments experience greater accounts receivable factoring activity.

Klapper (2000) presents a similar view. According to Klapper, factoring is particularly appealing in middle-income countries where it is more difficult for firms to raise working capital. Klapper also suggests that factoring is appealing in developing countries because information asymmetries between firms and lenders commonly make it difficult for firms to obtain financing. In addition, developing countries generally have weak governance systems including poor bankruptcy and secured transaction laws, which limit the use of real assets as collateral. Because accounts receivable are independent of a firm's business risk, an incentive exists for firms in developing countries to sell accounts receivable from high-quality customers as a source of short-term financing.

Berger and Udell (2004) note that highly opaque SMEs, which may not have access to loans from financial institutions, can often obtain financing through factoring. In addition, providing accounts receivable factoring services could be an attractive expansion opportunity for developing country bank or non-bank financial institutions to service the needs of small business clients. If done properly, banks and financial services firms can earn substantial profits while limiting their risk. By introducing or expanding their factoring services, such financial institutions can retain growing and profitable SME clients that they might otherwise forever lose. Perhaps more importantly, SMEs will have access to a new source of working capital financing that has been seriously lacking in the past.

In a comprehensive paper about the role of factoring in financing SMEs, Klapper (2006) investigates the determinants of factoring in 49 countries and finds that economic development, growth rate of GDP, the availability of credit information, and weakness in contract enforcement contribute to greater use of factoring. Klapper notes that while bank loans represent the primary source of SME financing in developed economies, they are often unavailable in emerging markets because they require lenders to be able to file liens against all business assets of the firm and require sophisticated technology and comprehensive credit information on firms. However, most developing countries do not have laws and judicial systems that sufficiently support the enforcement of contracts, nor do they possess the technological infrastructure or access to commercial credit information required. In addition, Klapper believes that factoring has a distinct advantage in providing funding to higher risk and informationally opaque firms, particularly in emerging economies, because factoring firms can base their purchase (lending) decision primarily on the creditworthiness of the firm paying the accounts receivable rather than on the client or borrower.

\section{GOVERNANCE AND THE OPERATION OF THE FINANCIAL SECTOR}

The rapid rise in factoring begs the question of why conventional intermediaries (banks) have not stepped up to meet the short term financing needs of a burgeoning class of small and medium enterprises in emerging economies? $^{1}$ The answer to this question lies in the unique character of financial intermediaries and the special complexity related to their governance in emerging economies. Caprio and Levine (2002) discuss this special complexity in an agency-theory framework. First, banks are more opaque than other industries so that there is greater informational asymmetry between insiders and outsiders. In most developing countries, conglomerates and the domination of large sectors of the economy by a few families, large organizations, or state owned enterprises create insider abuses and 'connected' lending, most likely at the expense of SMEs. Second, governments seek to diffuse ownership of banks by imposing restrictions on shareholding. Such restrictions are ineffective in limiting family dominance of banks, and in fact, protect them from market discipline in the form of a hostile takeover. Third, deposit insurance, whether explicit or implicit, and the rise of central banks as lenders of last resort lower the incentive of insured depositors to monitor bank managers. Fourth, government interventions in the form of minimum branching requirements, directed credit requirement, portfolio restrictions, liquidity requirements and 
limits on interest and fees are common in developing countries and these limit competitive forces in banking. Fifth, government regulators and supervisors are subject to a variety of political forces and may not enjoy much independence from the banks they regulate. Finally, in many emerging economies the government is an owner and also a regulator of banks. In such situations, bureaucrats can be expected to be less responsive to market forces and more responsive to political influence in allocating lending. All these problems mean that in emerging economies, weak governance mutes market discipline for the banks and biases them against small and medium enterprises.

At the center of factoring are future accounts receivable and the actions of two parties - the factor and the enterprise. The enterprise possesses a stream of future receivables but a need for current funds. The factor transforms the future receivables into immediate funds for the enterprise in exchange for a fee. ${ }^{2}$ In doing this, the factor profits from a bundle of services that it provides. These services include financing, credit services (which involves assessing the risk associated with the receivables being factored), and collection services (Klapper, 2006). The cost of these services is increasing in the opacity surrounding the activity of firms in an economy. At the same time, the factor enjoys a falling average cost with specialization (Mian and Smith, 1992; Smith and Shnucker, 1994). To an enterprise to which the accounts receivables are owed, the factor's service is a substitute to asset based shortterm finance (Summers and Wilson, 2000), which eases the constraint on working capital (Klapper, 2000). Factoring only requires the legal environment to sell accounts receivables. Factors face market discipline and the key to the success for a factor is in obtaining private information on the receivables, an activity, which is subject to economies of scale.

The quality of governance proxies the relative strength of law, practices and institutions in a country, and the severity of the information asymmetry problem caused thereby. It does not fully capture the actions and motivations of the public officials involved in shaping the laws and institutions and how they are implemented. If public officials are corrupt, then public oversight of governance of financial institutions becomes capricious so that the quality of the publicly available information about enterprises becomes unreliable. Also, the legal environment for transfer of ownership of accounts receivables from enterprises to the factors becomes weak. Therefore, for a given quality of governance, higher corruption increases the reliance on private information and increases the cost to factors. Additionally, higher corruption leads to a fall in investment (Mauro, 1995; Tanzi and Davoodi, 1997), and therefore, a fall in the demand for financial resources. Thus, corruption interacts with governance such that for a given quality of governance, an increase in incidence of corruption lowers accounts receivable factoring.

\section{DATA}

Data on annual factoring turnover by country was obtained from the Factor Chains International website. This data has been used in other studies about aggregate accounts receivable factoring activity (Klapper, 2006). Table 1 presents definitions of the variables used and the summary statistics. Country data for per capita GDP $(G D P)$, per capita GDP growth $(G D P G)$, net domestic credit provided to the private sector (NDC), gross capital formation (GCF), gross domestic saving (GDS), market capitalization of listed companies (MCLC), and the total values of stock traded (STTV) were obtained from the World Bank's World Development Indicators website. ${ }^{3}$

Table 1. Variable Descriptions and Summary Statistics

\begin{tabular}{|c|c|c|c|}
\hline Variable & $\begin{array}{c}\text { Definition } \\
\end{array}$ & Mean & Std Dev. \\
\hline FT & 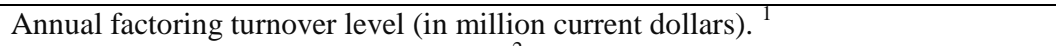 & $9,815.59$ & $25,683.01$ \\
\hline GDDP & Per capita GDP (in '00 current dollars). ${ }^{2}$ & 120.37 & 114.89 \\
\hline GGDP & Per capita GDP growth rate (in percent). ${ }^{2}$ & 3.71 & 3.01 \\
\hline GCF & Gross capital formation as a share of GDP. ${ }^{2}$ & 1.24 & 5.90 \\
\hline NDC & Net domestic credit provided to the private sector as a share of GDP (in percent). ${ }^{2}$ & 74.50 & 49.11 \\
\hline GDS & Gross domestic saving as a share of GDP(in percent). ${ }^{2}$ & 0.23 & 0.09 \\
\hline STTV & Total value of stocks traded as a share of GDP (in percent). ${ }^{2}$ & 0.38 & 0.54 \\
\hline MCLC & Market capitalization of listed stocks as a share of GDP (in percent). ${ }^{2}$ & 0.62 & 0.69 \\
\hline RISK & The overall perception of risk. ${ }^{3}$ & 9.09 & 2.11 \\
\hline TRADE & Trade GDP ratio (in percent). ${ }^{2}$ & 71.21 & 50.78 \\
\hline GI & Governance index. ${ }^{4}$ & 2.23 & 2.47 \\
\hline $\mathrm{CI}$ & Corruption index. $^{5}$ & 5.69 & 2.39 \\
\hline
\end{tabular}

Data sources are ${ }^{1}$ Factor Chain International; ${ }^{2}$ The World Development Indicators, The World Bank; ${ }^{3}$ The International Country Risk Guide, Political Risk Services; ${ }^{4}$ Kaufmann, Kraay, and Mastruzzi (2006); ${ }^{5}$ Transparency International. 
Data on the quality of governance (the governance index, GI) was constructed by aggregating the indices for 'governance effectiveness', 'regulatory quality', and 'rule of law' from the Worldwide Governance Indicators, presented in Kaufman, Kraay, and Mastruzzi (2006). 'Governance effectiveness' measures the quality of the civil service and the degree of its independence from political pressure, the quality of policy formulation and implementation, and the credibility of the government's commitment to such policies. The 'regulatory quality' index measures the ability of the government to formulate and implement sound policies and regulations that permit and promote private sector development. 'Rule of law' measures the extent to which economic agents have confidence in and abide by the rules of society, and in particular, the quality of law enforcement, the police and the courts, as well as the likelihood of crime and violence. Each of these indices range from -2.5 to 2.5 in value, and a higher number represents a higher quality of governance.

Corruption (the corruption index, CI) was measured by Transparency International's Corruption Perceptions Index. This index ranges from 1 to 10, and a higher number represents a lower incidence of corruption.

The overall perception of risk (RISK) to private enterprises is measured by the International Country Risk Guide's 'quality of investment' index. This index measures the risk associated with contract viability/expropriation, repatriation of profits, and payment delays. The index ranges from 0 to 12, and a higher number represents lower risk. The pair wise correlations for the variables are reported in Table 2.

Table 2. Pairwise Correlations

\begin{tabular}{|c|c|c|c|c|c|c|c|c|c|c|c|c|}
\hline & RISK & FT & GDPP & CI & NDC & GDPG & GCF & GDS & STTV & MCLC & GI & TRADE \\
\hline RISK & 1.00 & & & & & & & & & & & \\
\hline FT & 0.27 & 1.00 & & & & & & & & & & \\
\hline GDPP & 0.37 & 0.35 & 1.00 & & & & & & & & & \\
\hline CI & 0.42 & 0.22 & 0.83 & 1.00 & & & & & & & & \\
\hline NDC & 0.25 & 0.36 & 0.60 & 0.57 & 1.00 & & & & & & & \\
\hline GDPG & 0.00 & 0.17 & -0.19 & 0.17 & -0.16 & 1.00 & & & & & & \\
\hline GCF & -0.09 & 0.02 & -0.08 & 0.07 & -0.06 & -0.02 & 1.00 & & & & & \\
\hline GDS & 0.02 & 0.17 & 0.21 & 0.17 & 0.23 & 0.16 & 0.21 & 1.00 & & & & \\
\hline STTV & 0.23 & 0.36 & 0.47 & 0.44 & 0.59 & 0.03 & 0.06 & 0.20 & 1.00 & & & \\
\hline MCLC & 0.19 & 0.15 & 0.46 & 0.48 & 0.57 & 0.05 & 0.07 & 0.32 & 0.73 & 1.00 & & \\
\hline GI & 0.48 & 0.27 & 0.84 & 0.95 & 0.60 & -0.16 & 0.09 & 0.19 & 0.46 & 0.47 & 1.00 & \\
\hline TRADE & 0.19 & 0.49 & 0.23 & 0.21 & 0.19 & 0.10 & -0.04 & 0.50 & 0.19 & 0.49 & 0.25 & 1.00 \\
\hline
\end{tabular}

This table presents pairwise correlations of the variables used in this study.

\section{EMPIRICAL STRATEGY}

In the absence of an established theory explaining accounts receivable factoring, we use a reduced form model to study the extent to which its incidence is prevalent in economies with relatively weak financial and governance systems. We measure accounts receivable factoring activity in an economy by factoring turnover $(F T)$. Factoring is a financing arrangement, which is influenced by changes in business activity and the health of an economy's general macroeconomic environment. Changes in macroeconomic activity in this study are captured by per capita GDP $(G D P P)$ and the rate of growth of per capita GDP $(G D P G)$. A firm's use of accounts receivable factoring also depends on the development of an economy's financial system and the choices it offers. This study uses the market capitalization of listed companies $(M C L C)$ and total values of stock traded (STTV) to measure the development of a country's equities market. Net domestic credit provided by the banking sector (NDC) measures the amount of funds made available to firms by the banking system, and gross domestic savings (GDS) measures the surplus resources available for firms facing resource deficit in an economy. The demand for financing also depends upon the extent to which an economy's capital base is growing. This study uses gross capital formation $(G C F)$ to capture this growth. Finally, we use indices of governance $(G I)$, corruption $(C I)$, and risk to private investment $(R I S K)$ to measure the quality of governance, the incidence of corruption, and the perception of risk to private investment, respectively. 
The econometric model employed in this analysis is as follows:

$$
F T_{i, t}=F\left(\text { Control Variables } i_{i, t}\right)+G\left(\text { Governance Index }_{i, t}, \text { Corruption Index }_{i, t}\right)+\mu_{i}+\varepsilon_{i, t},
$$

where $\mu_{i}$ represent time invariant country fixed effects. We favor a panel data model because there is evidence in the literature that colonial history is significantly associated with the legal framework in a country (La Porta et. al., 1999). Also, a number of other country specific and time invariant factors like geographic location, religion and culture, ethnic heterogeneity etc., influence the determinants of factoring e.g., per capita GDP, gross domestic savings rate, governance and corruption (Islam, 1995; Loayza, Schmidt-Hebbel, and Servan,2000; Treisman, 2000). Note that in our data set the number of countries is fairly large compared to the number of years. ${ }^{4}$

$\varepsilon_{i, t}$ is assumed to be an identically and independently distributed random variable with zero mean. This assumption means that the same group of countries is followed over time. This is different from analysis of pooled cross sections over time where the idea is that during each year a new random sample is taken from the population.

Panel data present 'within' variation (i.e., variation over time in a country) and 'between' variation (i.e., variation between countries). If the same data generation process applies to all countries, then we have:

$$
F T_{i, t}=F\left(\text { Control Variables }_{i, t}\right)+G\left(\text { Governance Index }_{i, t}, \text { Corruption Index }_{i, t}\right)+u_{i, t}
$$

The data can be 'pooled' to use OLS (or GLS if there is autocorrelation or heterosckedasicity) and the estimates will be unbiased and efficient.

Our assumption is that the error term is not the same between countries.

$$
u_{i, t}=\mu_{i}+\varepsilon_{i, t}
$$

In this situation, we can pool the data only under the assumption that all explanatory variables are strictly independent of $\mu_{i}$. Even if this is tenable (and we say that it is not in our case), the composite error term $u_{i, t}$ becomes serially correlated because of $\mu_{i}$. Thus, pooled data will still lead to inefficient estimates. In this paper, we cannot pool the data because $\mu_{i}$ is correlated with some of the explanatory variables. For the same reason, we cannot use random effects estimation. With regard to the possibility of serial correlation and heterosckedasticity in the stochastic error term $\left(\varepsilon_{i, t}\right)$, we cannot rule out either and the asymptotic variance matrix estimator and the test statistics are adjusted following Woolridge (2002).

In our baseline model, we assume that the explanatory variables are uncorrelated with $\varepsilon_{\mathrm{it}}$, and linearly regress the level of annual factoring turnover by country (in millions of U.S. dollars) against the control variables. The control variables (GDPG, GDPP, GCF, GDS, MCLC, NDC, and STTV) are the macroeconomic variables discussed in the literature as influencing the volume of factoring activity in an economy. After estimating the baseline model using the control variables, measures of governance (GI) and corruption (CI) were added as explanatory variables to determine how they affect the level of factoring turnover. We test for the robustness of these estimates by controlling for the perception of risk (RISK) to private investment and the degree of openness measured by the trade/GDP ratio. We then relax the assumption of strict exogeneity, with respect to per capita gross domestic product (GDPP) and net domestic credit supplied to the private sector (NDC), and obtain an instrumental variable (IV) estimate of the model. Finally, we investigate the determinants of the growth in annual factoring turnover by treating the logarithm of annual factoring turnover as the dependent variable. 


\section{EMPIRICAL RESULTS}

Given the assumption that at least some of the explanatory variables in Equation 1 are correlated with the time invariant country fixed effects $\left(\mu_{i}\right)$, we obtain a fixed effect (FE) estimate of alternative linear specifications of the model. ${ }^{5}$ In all cases, an $F$ - test rejects the null hypothesis that all $\mu_{i}$ are zero. Table 3 reports the estimates obtained for different specifications.

Column 1 of Table 3 reports the model in Equation 1 estimated with the control variables only. The results show that factoring turnover increases with the level of per capita gross domestic product (GDPP) and gross capital formation (GCF) and decreases with the rate of savings (GDS).

With respect to the explanatory variables relating to the financial system, we find that all corresponding coefficients are economically and statistically significant. In economies where net domestic credit to the private sector (NDC) as a ratio of GDP is high, factoring turnover (FT) also is high. According to Klapper (2006), the relationship between accounts receivable factoring activity and measures of bank credit is ambiguous because factoring may be a complement to banking services in countries with extensively developed financial systems and a substitute in countries poorly developed financial systems.

Table 3. The Determinants of Factoring Turnover

\begin{tabular}{|c|c|c|c|c|c|c|c|c|}
\hline Variable & 1 & 2 & 3 & 4 & 5 & 6 & 7 & 8 \\
\hline \multirow[t]{2}{*}{ GDPP } & 20.27 & 23.72 & 25.57 & 36.65 & 25.21 & 20.15 & 21.29 & $22.51^{\mathrm{a}}$ \\
\hline & $(0.00)$ & $(0.00)$ & $(0.00)$ & $(0.00)$ & $(0.02)$ & $(0.00)$ & $(0.00)$ & $(0.01)$ \\
\hline \multirow[t]{2}{*}{ GGDP } & -10.45 & -9.25 & -11.81 & -16.30 & -15.27 & & & \\
\hline & $(0.26)$ & $(0.54)$ & $(0.44)$ & $(0.39)$ & $(0.39)$ & & & \\
\hline \multirow[t]{2}{*}{ GCF } & 9.92 & 33.01 & 19.59 & 12.86 & 42.83 & 41.13 & 38.14 & $0.03^{\mathrm{a}}$ \\
\hline & $(0.01)$ & $(0.02)$ & $(0.02)$ & $(0.61)$ & $(0.11)$ & $(0.11)$ & $(0.09)$ & $(0.14)$ \\
\hline \multirow[t]{2}{*}{ NDC } & 47.44 & 63.02 & 68.42 & 48.34 & 52.53 & 59.50 & 49.67 & $118.48^{\mathrm{a}}$ \\
\hline & $(0.06)$ & $(0.11)$ & $(0.09)$ & $(0.23)$ & $(0.17)$ & $(0.09)$ & $(0.15)$ & $(0.03)$ \\
\hline \multirow[t]{2}{*}{ GDS } & -30.18 & -37.97 & -34.32 & -21.43 & -21.83 & -30.00 & -29.76 & -131.59 \\
\hline & $(0.02)$ & $(0.05)$ & $(0.06)$ & $(0.33)$ & $(0.30)$ & $(0.11)$ & $(0.12)$ & $(0.51)$ \\
\hline \multirow[t]{2}{*}{ STTV } & 69.13 & 91.30 & 87.52 & 91.52 & 94.29 & 94.32 & 92.13 & 72.99 \\
\hline & $(0.00)$ & $(0.02)$ & $(0.02)$ & $(0.04)$ & $(0.04)$ & $(0.03)$ & $(0.04)$ & $(0.00)$ \\
\hline \multirow[t]{2}{*}{ MCLC } & -31.41 & -58.18 & -54.09 & -79.92 & -73.80 & -72.30 & -60.84 & -63.40 \\
\hline & $(0.08)$ & $(0.05)$ & $(0.06)$ & $(0.02)$ & $(0.03)$ & $(0.02)$ & $(0.04)$ & $(0.00)$ \\
\hline \multirow[t]{2}{*}{ RISK } & & & & & 89.31 & 92.60 & 105.52 & 83.15 \\
\hline & & & & & $(0.04)$ & $(0.00)$ & $(0.00)$ & $(0.05)$ \\
\hline \multirow[t]{2}{*}{ TRADE } & & & & & & & -87.43 & 9.56 \\
\hline & & & & & & & $(0.07)$ & $(0.86)$ \\
\hline \multirow[t]{2}{*}{ GI } & & -26.52 & -10.55 & -55.39 & -59.75 & -64.25 & -67.33 & -79.50 \\
\hline & & $(0.01)$ & $(0.09)$ & $(0.02)$ & $(0.02)$ & $(0.00)$ & $(0.00)$ & $(0.00)$ \\
\hline \multirow[t]{2}{*}{$\mathrm{GI}^{2}$} & & & -72.30 & -13.42 & -13.11 & -12.49 & -12.34 & -13.33 \\
\hline & & & $(0.00)$ & $(0.00)$ & $(0.01)$ & $(0.01)$ & $(0.00)$ & $(0.00)$ \\
\hline \multirow[t]{2}{*}{ CI x GI } & & & & 12.66 & 12.21 & 13.01 & 12.99 & 15.51 \\
\hline & & & & $(0.06)$ & $(0.06)$ & $(0.03)$ & $(0.03)$ & $(0.00)$ \\
\hline Within $\mathrm{R}^{2}$ & 0.17 & 0.21 & 0.23 & 0.30 & 0.31 & 0.30 & 0.31 & \\
\hline Wald test ( $p$-value) & 0.00 & 0.04 & 0.05 & 0.04 & 0.00 & 0.00 & 0.00 & 0.00 \\
\hline No. of observations & 525 & 355 & 355 & 296 & 296 & 317 & 317 & 275 \\
\hline No. of countries & 59 & 59 & 59 & 58 & 58 & 62 & 62 & 62 \\
\hline
\end{tabular}

The dependent variable in the above regressions is annual factoring turnover (in million \$). p-values are reported beneath their respective coefficients in parentheses. Coefficients on GGDP, GI, and $\mathrm{GI}^{2}$ are divided by 10 . GCF, NDC, GDS, STTV, MCLC, and TRADE are as a share of GDP. The coefficient on GDS is divided by 100 . Column 8 reports 2 SLS estimates. ${ }^{a}$ represents coefficients instrumented by own lagged value.

The coefficient for variable market capitalization of listed companies (MCLC) as a ratio of GDP is negative and weakly significant. One possible explanation for this result is that firms in countries with larger and more 
developed equity markets rely less on expensive factoring arrangements to raise working capital. Interestingly, on the other hand, the coefficient for the value of stocks traded as a ratio of gross domestic product (STTV) is positive and significant, indicating that higher equity market turnover is associated with greater accounts receivable factoring activity. In general, greater equity market trading activity (liquidity) suggests that stock market participants are more confident in the integrity of the equity markets. Thus, it would seem reasonable to conclude that the relationship between factoring activity and equity market activity is positive because factoring, a short term financial arrangement, would complement long-term equity as a source of financing.

In column 2 of Table 3, the primary variable of interest in this research, the quality of governance (GI), is added as an explanatory variable to the regression. The results show that the coefficient for GI is negative and significant. As we expected, this suggests that countries with weak governance experience greater accounts receivable factoring activity. The results are also economically significant. To better understand the impact of poor governance on factoring activity, consider the difference in the magnitude of factoring activity between two countries over two points in time. The GI index for Lebanon in 2000 was -0.24 , and the GI index for Greece in 2005 was 2.46. Our estimates indicate that for such difference in the quality of governance between two countries in a given year, the difference in the annual factoring turnover will be over $\$ 4$ billion - other things remaining the same.

Column 3 of Table 3 shows that the influence of poor governance (GI) is sharply non-linear. The coefficient for the square of GI is negative in sign and significant. In addition, when GI squared is added as an explanatory variable, the coefficient for the level of GI becomes measurably smaller and its statistical significance is weak. Table 1 column 4 shows that adding the corruption index (CI) to the model results in a very large change in the size of the coefficient for GI. Adding CI results in a GI that is more than twice as large and less non-linear compared to the model in column 3 . This suggests that for a given value of GI, an increase in corruption (a decrease in the value of the interaction term GI x CI) leads to a lower factoring turnover level. This may have resulted due to a number of factors. First, corruption lowers investment and the level of economic activity in an economy (Mauro, 1995; Swaleheen, 2007), which acts to reduce the demand for working capital. Second, in the presence of significant corruption, small and medium enterprises can get around the problem of information asymmetry, and consequential difficulty in getting working capital from conventional sources, by bribing. Third, corruption weakens the property right over an accounts receivable so that a primary condition for factoring to work becomes absent.

Two important aspects of the non-linearity in the effect of GI are observed when we compare the model in column 4 to the model in column 3. First, non-linearity in the effect of governance is weaker when we control for the interaction between corruption (CI) and governance (GI). This suggests that how governance affects a firm's access to short term finance in an economy depends on the prevailing degree of corruption. Second, when the nonlinearity of GI and the interaction between GI and CI is controlled, the coefficients for net domestic credit to the private sector (NDC) and gross domestic saving (GDS) cease to be statistically significant. This suggests that while the use of factoring is motivated by an overall lack of savings and weakness in financial intermediation, weakness in governance and the absence of corruption has a more primary role in this outcome.

In column 5, we add quality of investment $(R I S K)$ as an explanatory variable. The estimated coefficient for this variable has a positive sign and it is statistically significant. Thus, in countries where the risk to investment is high (the RISK variable is low), factoring turnover is low. Comparison of columns 4 and 5, reveal that when RISK is added as an explanatory variable, there is little change in any other coefficient estimates. This suggests that the effect of risk to investment on factoring is more direct than indirect.

In all the alternative specifications of the model discussed so far, we find that the GDP growth rate is not a statistically significant determinant of the level of aggregate factoring activity in an economy. In column 6, we report estimates obtained for a model in which this variable is not included. A comparison with column 5 does not indicate any qualitative change in the coefficient estimates, which implies that the GDP growth rate is not a significant determinant of the level of factoring turnover. We also added openness of an economy, measured by the trade/GDP ratio as an explanatory factor (column 7). The estimated coefficient for this variable is not significant and, by comparing column 7 to column 6 , we see very little change in the other coefficient estimates. 
The models in columns 1 to 7 , are all estimated under the assumption that the error term $\varepsilon_{i, t}$ is uncorrelated with all of the explanatory variables. In column 8 , we report the estimates for a model where we assume that per capita gross domestic product (GDPP), gross capital formation (GCF), and credit to private sector as a ratio of gross domestic product (NDC), are weakly exogenous in the sense that $\varepsilon_{i, t}$ is uncorrelated with the past realization of these variables. The assumption of weak exogeneity allows us to instrument GDPP, GCF, and NDC by respective lagged values. ${ }^{6}$ The 2 SLS results are reported in column 8 . By comparing columns 7 and 8 , we find that the coefficients for our variables of interest: governance, governance squared, and the interaction between governance and corruption, are more or less unaffected in terms of size, sign and statistical significance. The coefficient for gross capital formation (GCF) is no longer significant (economically or statistically). On the other hand, credit to private sector as a ratio of GDP (NDC) is now sizably more significant economically and also statistically significant (compare column 8 to column 1), indicating that this is an important channel through which the negative indirect effects some of the other determinants of factoring turnover are transmitted.

Finally, we examined the factors that determine the rate of growth of factoring in a country by treating the logarithm of annual factoring turnover as the dependent variable. The results are reported in Table 4 . The estimates reported in column 1 of Table 4 measure the difference in the growth rate of factoring turnover in percentage terms from a unit change in the corresponding explanatory variable. For example, if the governance index (GI) is higher by one, the growth rate of factoring turnover (FT) will be higher by 0.86 percentage points. The results in column 1 indicate the per capita gross domestic product (GDPP), the value of stocks traded as a share of gross domestic product (STTV), the market capitalization of listed companies as a share of gross domestic product (MCLC) and the quality of governance (GI) are statistically significant determinants of the growth in factor turnover. However, the value of stocks traded is only significant at the $10 \%$ level. Similarly, the coefficient of market capitalization of traded companies in model one is only significant at the $10 \%$ level. Therefore, these empirical results highlight the importance of GDP and quality of governance as determinants of factoring turnover.

Table 4. The Determinants of Growth in Factoring Turnover

\begin{tabular}{|c|c|c|}
\hline Variable & 1 & 2 \\
\hline GDPP & $\begin{array}{c}0.02 \\
(0.00)\end{array}$ & $\begin{array}{c}0.02 \\
(0.00)\end{array}$ \\
\hline GDPG & $\begin{array}{c}-0.02 \\
(0.31)\end{array}$ & $\begin{array}{c}-0.03 \\
(0.20)\end{array}$ \\
\hline GCF & $\begin{array}{c}- \\
(0.90)\end{array}$ & $\begin{array}{c}- \\
(0.93)\end{array}$ \\
\hline NDC & $\begin{array}{c}- \\
(0.57)\end{array}$ & $\begin{array}{c}- \\
(0.39)\end{array}$ \\
\hline GDS & $\begin{array}{c}2.45 \\
(0.35)\end{array}$ & $\begin{array}{c}4.25 \\
(0.19)\end{array}$ \\
\hline STTV & $\begin{array}{l}-0.51 \\
(0.08)\end{array}$ & $\begin{array}{c}-0.5 \\
(0.09)\end{array}$ \\
\hline MCLC & $\begin{array}{c}0.45 \\
(0.06)\end{array}$ & $\begin{array}{c}0.56 \\
(0.03)\end{array}$ \\
\hline GI & $\begin{array}{c}0.34 \\
(0.02)\end{array}$ & $\begin{array}{c}0.86 \\
(0.00)\end{array}$ \\
\hline $\mathrm{GI}^{2}$ & & $\begin{array}{l}-0.15 \\
(0.00)\end{array}$ \\
\hline CI x GI & & $\begin{array}{c}0.01 \\
(0.88)\end{array}$ \\
\hline Within $\mathrm{R}^{2}$ & 0.12 & 0.19 \\
\hline No. of observations & 306 & 266 \\
\hline No. of countries & 59 & 57 \\
\hline
\end{tabular}

The dependent variable in the above regressions is annual factoring turnover (in million \$). p-values are reported beneath their respective coefficients in parentheses. GCF, NDC, GDS, STTV, and MCLC are as a share of GDP. A dash indicates value close to zero. 
It is important to note the independent variables affect the growth of factoring turnover differently compared to how they affect the level of level of factor turnover. The level of factoring turnover is increasing in the value of stocks traded as a ratio of GDP and decreasing in market capitalization as a share of GDP and the quality of governance. However, the growth of factoring turnover is affected by these variables in an opposite direction. The growth rate of factoring turnover is low in countries with a high value of stocks traded as a share of GDP and high in countries where market capitalization of listed companies as a share of GDP and the quality of governance is high. Starting from a given point in time and a given level of factoring, if agents become myopic because current information is more reliable than future information (so that stock traded as a share of GDP increases); there is less use of factoring. On the other hand, if information asymmetry is reduced (i.e., the quality of governance improves), and there is greater use of the stock market to raise equity, there is greater use of factoring.

\section{CONCLUSION}

The quality of governance has a complex and critically important relationship with how the financial sector operates in an economy. Weak governance creates incentives for the banking system to under-serve small and medium enterprises. There is growing evidence that small and medium enterprises in emerging economies use accounts receivable factoring to meet their working capital needs. The literature ascribes this to information asymmetry that puts such enterprises at a disadvantage. This paper extends the literature by analyzing accounts receivable factoring in the context of the root of information asymmetry - weak governance. We present evidence that countries with weak governance have higher levels of accounts receivable factoring while the growth of factoring in a country is positively associated with improvement in governance. We also present evidence that given the quality of governance, firms' use of factoring is decreasing in the incidence of corruption. Thus, information asymmetry makes it more difficult for SMEs to meet their working capital needs if the country is more corrupt.

\section{ENDNOTES}

${ }^{1}$. Small companies have no known reputation and face high cost of borrowing. Medium sized companies tend to make greater use of bank finance. Large companies can attract funds from the capital market. Small and medium companies are considered to be engines of growth in developing countries (See Tsumba, 2002, p 288).

2. The fee is a percentage of the receivables, and in the absence of data, we assume that it is the same for all countries and all years. In addition, we assume that all factoring is on a 'non-recourse' basis meaning that the factor assumes the title to the receivables factored and the enterprise is free of responsibility about future performance of the receivables.

3. The World Bank. http://www.worldbank.org/

4. i.e. $(\mathrm{N} \rightarrow \infty, \mathrm{T}$ fixed) as opposed to $(\mathrm{T} \rightarrow \infty, \mathrm{N}$ fixed) so that we are not concerned about unit root and cointegration problems.

5. A Hausman-Taylor test rejected the null hypothesis that $\mu_{i}$ is uncorrelated with the explanatory variables.

6. The first stage regression of the endogenous variables on all exogenous variables and instruments are all significant; also, the coefficients for the instruments are all significant.

\section{AUTHOR INFORMATION}

Daniel J. Borgia, Ph.D. is an Associate Professor of Finance in the Lutgert College of Business at Florida Gulf Coast University and Director of the China Studies Institute. He is a founding faculty member of Florida Gulf Coast University and a 2002 - 2003 China Fulbright Scholar at Nanjing University. His research interests are in the areas of regional economic development issues, business exporting, entrepreneurship, regional unemployment, third world capital market development, the impact on economic development resulting from tax law changes, business and personal financial planning, and financial education.

Mushfiq Swaleheen, Ph.D. is an Assistant Professor of Economics in the Lutgert College of Business at Florida Gulf Coast University. Dr. Swaleheen has extensive international work experience as well as experience in teaching economics. His research interests are in the areas of applied econometrics, causes and consequences of corruption, economic development, and international economics. 
Travis L. Jones, Ph.D. is an Assistant Professor of Finance in the Lutgert College of Business at Florida Gulf Coast University. Dr. Jones is a registered investment advisor, series 3 certified futures broker, and Senior Investment Strategy Advisor at Laureola Asset Management, in Naples, FL. His research interests are in the areas of risk management, single-stock futures, initial public offerings, and international finance.

H. Shelton Weeks, Ph.D. is a Professor of Finance \& Real Estate in the Lutgert College of Business at Florida Gulf Coast University and director for the Lucas Institute for Real Estate Development \& Finance. He is also the director of the internship program for finance and real estate. His research interests include real estate, pedagogical issues, corporate governance, and international finance.

\section{REFERENCES}

1. Bakket, M.H.R., Klapper, L., Udell, G.F., Financing small and medium-size enterprises with factoring: Global growth in factoring - and its potential in Eastern Europe, The World Bank, Warsaw, Poland, 2004.

2. Berger, A., Udell, G., A more complete conceptual framework for SME finance, The World Bank, MC 13121, 2004.

3. Bushman, R.M., Smith, A.J., Transparency, financial accounting information, and corporate governance, Economic Policy Review, Vol. 9, pp. 65-87, 2003.

4. Caprio, G., Levin, R., Corporate governance in finance: Concepts and international observations, in: Litan, R.E., Pomerleano, M., Sundararajan, V. (Eds.), Financial Sector Governance: The Roles of the Public and Private Sectors, Brookings Institution Press, Washington, D.C., pp. 17-49, 2002.

5. Islam, N., Growth empirics: A panel data approach, The Quarterly Journal of Economics, Vol. 110, No. 4, pp. 1127-1170, 1995.

6. Kaufmann, D., Kraay, A., Mastruzzi, M., Governance matters v: Governance indicators for 1996-2002, The World Bank Policy Research Working Paper 3106, 2006.

7. Klapper, L., Determinants of global factoring, The World Bank, 2000.

8. Klapper, L., The role of factoring for financing small and medium enterprises, Journal of Banking \& Finance, Vol. 30, pp. 3111-3130, 2006.

9. Litan, R.E., Pomerleano, M., Sundararajan, V., Strengthening financial sector governance in emerging markets, in: Litan, R.E., Pomerleano, M., Sundararajan, V. (Eds.), Financial Sector Governance: The Roles of the Public and Private Sectors, Brookings Institution Press, Washington, D.C., pp. 1-13, 2002.

10. Lotz, B., Factoring may boost your company's cash flow. Business Credit, Vol. 94, No. 7, pp. 38-39, 1992.

11. Loayza, N., Schmidt-Hebbel, K., Servan, L., What drives private saving around the world?, The Review of Economics and Statistics, Vol. 82, No. 2, pp. 165-181, 2000.

12. Mauro, P., Corruption and growth, Quarterly Journal of Economics, Vol. 110, pp. 681-712, 1995.

13. Mian, S.L., Smith, C., Accounts receivable management policy: Theory and evidence, Journal of Finance, Vol. 47, No. 1, pp. 169-200, 1992.

14. Schumpeter, J.A., The Theory of Economic Development, Harvard University Press, Cambridge, 1911.

15. Smith J., Schnucker, C., An empirical examination of the organizational structure: The economics of the factoring decision, The Journal of Corporate Finance: Contracting, Governance and Organization, Vol. 1, No. 1, pp. 1119-138, 1994.

16. Spragins, E., Quick cash, Inc., Vol. 13, No. 3, pp. 95-96, 1991.

17. Summers, B., Wilson, N., Trade credit management and the decision to use factoring: An empirical study, Journal of Business Finance \& Accounting, Vol. 27, No. 1, pp. 37-68, 2000.

18. Swaleheen, M., Corruption and investment choices: A panel data study, Kyklos, Vol. 60, No. 4, pp. 601616, 2007.

19. Tanzi, V., Davoodi, V., Corrruption, Public investment and growth, IMF Working Paper No. WP/97/139, 1997.

20. Treisman, D., The causes of corruption: A cross national study, Journal of Public Economics, vol. 76, pp. 399-457, 2000.

21. Tsumba, L.L., How can banks exert better governance on corporations? The Zimbabwe experience, in: Litan, R.E., Pomerleano, M., Sundararajan, V. (Eds.), Financial Sector Governance: The Roles of the Public and Private Sectors, Brookings Institution Press, Washington, D.C., pp. 285-300, 2000.

22. Wooldridge, J.M., Econometric Analysis of Cross Section and Panel Data, The MIT Press, 2002. 
NOTES 